\title{
Detection of GB virus $C$ genomic sequence in the cerebrospinal fluid of a HIV-infected patient in China: a case report and literature review
}

\author{
Z. $\mathrm{LIU}^{1} \dagger, \mathrm{Y} \cdot \mathrm{ZHANG}^{1} \dagger, \mathrm{F} \cdot \mathrm{WEI}^{2}, \mathrm{M} \cdot \mathrm{XU}^{1}, \mathrm{D} \cdot \mathrm{MOU}^{1}, \mathrm{~T} \cdot \mathrm{ZHANG}^{1}, \mathrm{~W} \cdot \mathrm{LI}^{1}$, \\ D. $\mathrm{CHEN}^{2} *$ AND H. WU ${ }^{1} *$ \\ ${ }^{1}$ STD/AIDS Research Center, Beijing Key Laboratory, Beijing You An Hospital, Capital Medical University, \\ Beijing, China \\ ${ }^{2}$ Beijing Institute of Hepatology, Beijing, China
}

Received 25 November 2014; Final revision 17 April 2015; Accepted 30 May 2015;

first published online 17 June 2015

\section{SUMMARY}

Hepatitis $\mathrm{G}$ virus or GB virus $\mathrm{C}(\mathrm{GBV}-\mathrm{C})$ is a human virus of the Flaviviridae family that is structurally and epidemiologically closest to hepatitis $\mathrm{C}$ virus, but replicates primarily in lymphocytes. Co-infection with GBV-C has been reported to confer beneficial outcomes in some HIV-positive patients. Up to now, however, studies on GBV-C infection in the central nervous system (CNS) of HIV-infected patient have rarely been reported. Herein, we report on a 32-year-old HIV-1-infected patient with cerebral toxoplasmosis and fungal encephalitis. GBV-C viral loads were detected in CSF by quantitative real-time reverse transcription polymerase chain reaction (RTPCR), and the results showed that GBV-C viral load was 6.5 log copies $/ \mathrm{ml}$. We amplified and sequenced the E2 and 5'-untranslated regions from the purified viral RNA from CSF by RT-PCR. Both sequences belong to genotype 3 and there were some minor nucleotide divergence among the E2 sequences from the CSF of the patient. These data suggest that GBV-C may be able to penetrate the blood-brain barrier and colonize the CNS of HIV-infected patients. However, the exact mechanisms and potential effect of the infected GBV-C in CNS on HIV-associated neuropathy needs to be further explored.

Key words: Cerebrospinal fluid (CSF), encephalitis, GB virus C, human immunodeficiency virus type 1.

\section{INTRODUCTION}

GBV-C is a human virus of the Flaviviridae family that is structurally and epidemiologically closest to hepatitis $\mathrm{C}$ virus (HCV). Commonly, only $1-4 \%$ of healthy blood donors have GBV-C viraemia at the time of blood donation in the USA [1, 2]. A high prevalence (up to $50 \%$ ) of active (GBV-C viraemia)

\footnotetext{
* Author for correspondence: Dr D. Chen or Dr H. Wu, No. 8 Xi Tou Tiao You An Men Wai, Beijing 100069, P.R. China. (Email: dexi09@yahoo.com) [D.C.] (Email: haow99@gmail.com) [H.W.]

$\uparrow$ Served as joint first authors.
}

or prior (emergence of anti-E2) GBV-C infection is observed in HIV-infected patients since similar transmission [3-5]. GBV-C replicates primarily in T and $\mathrm{B}$ lymphocytes and in peripheral blood mononuclear cells $[6,7]$, and poorly, if at all, in hepatocytes [8-10]. Transmission routes of GBV-C through parenteral and sexual contact [11, 12], and vertically from mother to child have been documented, and GBV-C infection is common in many populations $[5,13]$. Although GBV-C is initially thought to be associated with chronic hepatitis, extensive investigation has failed to identify any association between this virus and any clinical illness. In contrast with $\mathrm{HCV}$, a 
number of studies have reported HIV-positive patients co-infected with GBV-C to achieve beneficial outcomes [13-15]. However, some contradictory reports regarding the effects of GBV-C on the course of HIV infection are present $[16,17]$.

The effect of GBV-C/HIV-1 co-infection on the progress of HIV-infected disease is still not well known. Some evidence has demonstrated the molecular interactions between these two viruses [18-20]. GBV-C is commonly detected in the blood of HIV-infected patients; up to now, however, studies on GBV-C infection in the central nervous system (CNS) of HIV-infected patients have rarely been reported. In this paper, we report on a HIV-1infected patient with detectable GBV-C viraemia in the cerebrospinal fluid (CSF). However, the neuropathological effect of GBV-C viraemia in CSF on HIV-infected patients needs to be further explored.

\section{CASE REPORT}

A 32-year-old Wa ethnic minority male (designated $\mathrm{YN}$ ) with a 1-year history of abnormal gait and insecure balance from Yunnan province was diagnosed with HIV-1 infection in 2006. The patient had a previous diagnosis of tuberculous meningitis with confusion and fever as well as limb ataxias 2 years ago, which was cured with 1 year of anti-tubercle bacillus therapy combined with isoniazid, rifampicin, pyrazinamide and ethambutol. At that time, the patient started to receive continuous antiretroviral therapy including AZT, 3TC and EFV. The clinical data and laboratory test results showed that the HIV RNA viral load of the patient was $<50$ copies $/ \mathrm{ml}$ and the CD4+ T cell count was 179 cells $/ \mathrm{mm}^{3}$ at the time of admission. Brain MRI showed a hypodense lesion $6 \mathrm{~mm}$ in diameter, and contrast-enhancing focal brain lesion in the left Sylvian cistern. In CSF, total white blood cell count was $48 \times 10^{6} / 1(75 \%$ neutrophils, $25 \%$ monocytes), protein was $2 \cdot 0 \mathrm{~g} / \mathrm{l}$, glucose was $2.44 \mathrm{mmol} / \mathrm{l}$ and chloride was $112.0 \mathrm{mmol} / \mathrm{l}$. HIV RNA viral load in CSF was 3560 copies $/ \mathrm{ml}$. CSF and culture staining for mycobacterial and bacterial tests were negative during Lyme, venereal disease research laboratory test and cryptococcal antigen detection, but fungal spores were detected in the CSF. This patient was primarily diagnosed as cerebral toxoplasmosis and fungal encephalitis. The detailed characteristics of this case are given in Table 1 .
Table 1. Demographics and clinical characteristics of the case

\begin{tabular}{ll}
\hline \hline Item & Value \\
\hline Age (years) & 32 \\
Gender & Male \\
Duration of HIV infection & $\begin{array}{l}\text { Approximately 2 years from } \\
\text { diagnosis of HIV }\end{array}$ \\
Ethnicity & Wa nationality \\
Transmission route & Intravenous drug use \\
HIV infection stage & CDC 3 \\
Combined antiretroviral & AZT, 3TC and EFV \\
therapy & $179(600-1000)$ \\
CD4+ cell count on & \\
admission (cells/mm $\left.{ }^{3}\right)$ & \\
HIV-1 viral load on & \\
admission & \\
In blood (copies/ml) & $<50$ \\
In CSF (copies/ml) & 3560 \\
Neurological complications & Cerebral toxoplasmosis, \\
& fungal encephalitis \\
Laboratory test of CSF & \\
Total white blood cell count & $48(0-8)$ \\
( $\times 10^{6}$ cells/l) & \\
Protein (g/l) & $2 \cdot 0(0-0 \cdot 4)$ \\
Glucose (mmol/l) & $2 \cdot 44(2 \cdot 5-4 \cdot 5)$ \\
Chloride (mmol/l) & $112 \cdot 0(120-132)$ \\
Fungal spores & + \\
Mycobacterial & - \\
Bacterial & - \\
\hline \hline
\end{tabular}

Values given in parentheses are the normal range for the tests.

\section{MATERIALS AND METHODS}

Viral RNA was purified from CSF stored at $-80^{\circ} \mathrm{C}$ using the QIAamp Viral RNA kit (Qiagen, Germany) according to the manufacturer's protocol. $E 2$ and $5^{\prime}-N C R$ genes were amplified and sequenced. Detailed experimental procedures were as follows: the purified RNA was subjected to RT-PCR amplification with $2.5 \mu \mathrm{g}$ total RNA in $25 \mu \mathrm{l} \mathrm{RT}$ reaction mix at $37^{\circ}$ $\mathrm{C}$ for $50 \mathrm{~min}$ using random hexamers as the primers (SuperScript III First-Strand Synthesis System for RT-PCR, Invitrogen USA). The RT-PCR products were selected as the templates for the nested PCR (primers specific for E2 and 5'-NCR are given in Table 2). Multiple GBV-C negative controls were applied to detect any possible contaminations. PCR was performed in a 9600 Thermal Cycler (Applied Biosystems, USA) with a primer concentration of $400 \mathrm{~nm}$ and template concentration of $100 \mathrm{~nm}$ in the PCR reaction mix. RT-PCR parameters included pre-denaturation at 


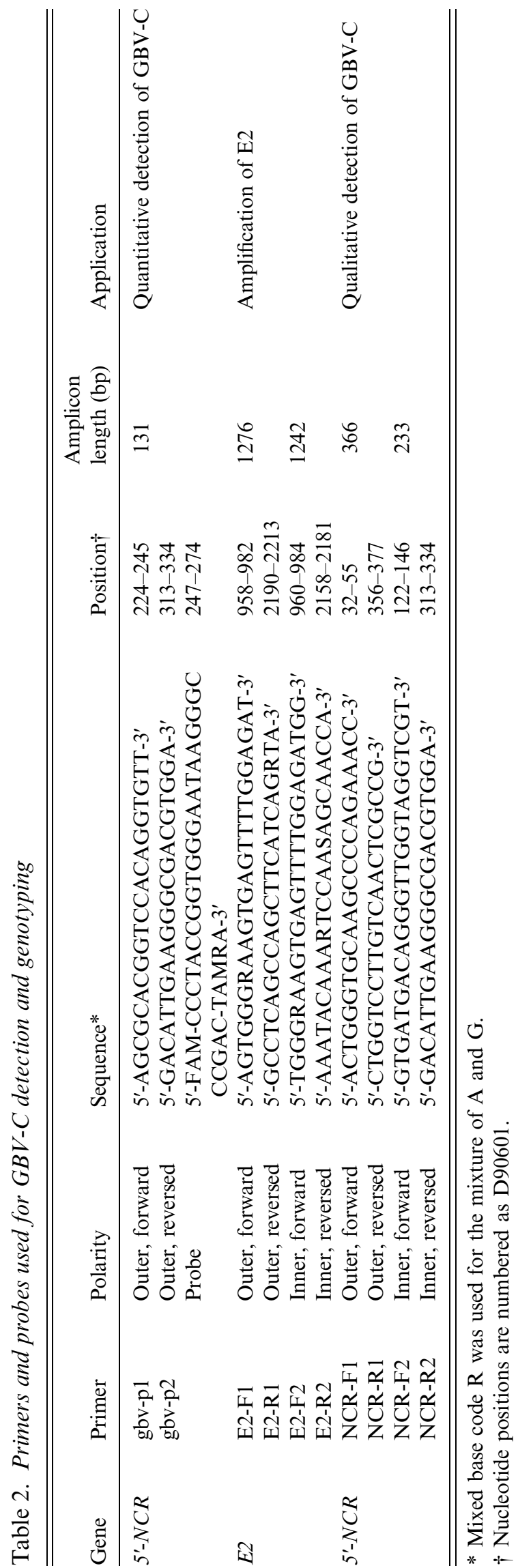

$94{ }^{\circ} \mathrm{C}$ for $2 \mathrm{~min}$ and then 30 amplification cycles with denaturation at $94{ }^{\circ} \mathrm{C}$ for $15 \mathrm{~s}$, annealing at $50^{\circ} \mathrm{C}$ for $30 \mathrm{~s}$ and extension at $72{ }^{\circ} \mathrm{C}$ for $45 \mathrm{~s}$, followed by a supplementary extension at $72{ }^{\circ} \mathrm{C}$ for $10 \mathrm{~min}$. For the amplification of the $5^{\prime}-N C R$ gene, the detailed experimental procedures were same as previously reported [21]. PCR products of $E 2$ were cloned using the TA cloning system (Takara, China), and randomly selected clones were sequenced on an ABI 3730 Genetic Analyzer (Applied Biosystems). The E2 sequences from each clone were aligned with reference sequences from different GBV-C genotypes available from GenBank (NCBI website) by the neighbour-joining sequence alignment program of Mega 5.0 software (mega.software.informer.com/5.0/). The PCR product of $5^{\prime}$-NCR from the CSF was directly sequenced and aligned with reference sequences by the maximum composite likelihood model implemented in the Mega 5.0 software package.

Then, GBV-C viral load in the CSF was evaluated by quantitative real-time PCR (qPCR), using the same method as a previously published study [21]. Briefly, a standard curve of the GBV-C NCR plasmid was quantified using the universal qPCR method in a $25 \mu \mathrm{l}$ reaction containing $1 \times$ Taqman Universal PCR Master Mix (Applied Biosystems), 400 nм primer gbv-p1, $400 \mathrm{~nm}$ primer gbv-p2 and $200 \mathrm{~nm}$ fluorescent probe gbv-probe (Invitrogen, China) (the primers and probe sequences are given in Table 2). Serial tenfold dilutions of GBV-C NCR plasmid were used to cover a range of $10^{4}-10^{7}$ molecules per reaction. The results indicated that GBV-C viral load was $6.5 \mathrm{log}$ copies $/ \mathrm{ml}$ in the CSF. Furthermore, in order to test the incidence of GBV-C in the CSF of HIV/AIDS patients, the $5^{\prime}-N C R$ and $E 2$ genes of paired blood and CSF from five HIV-positive patients (designated BJ40, BJ42, BJ51, BJ76, BJ102) who were co-infected with GBV-C without the symptoms of opportunistic brain infection were amplified.

\section{RESULTS}

Both 5'-NCR (233 bp product) and E2 (1242 bp product) genes were successfully amplified from the CSF of patient YN. Regarding the five patients (BJ40, BJ42, BJ51, BJ76, BJ102) without opportunistic CNS infection, both $5^{\prime}-N C R$ and $E 2$ genes were positive in the blood, but were absent from all paired CSF. The phylogenetic tree from the E2 region showed that all 


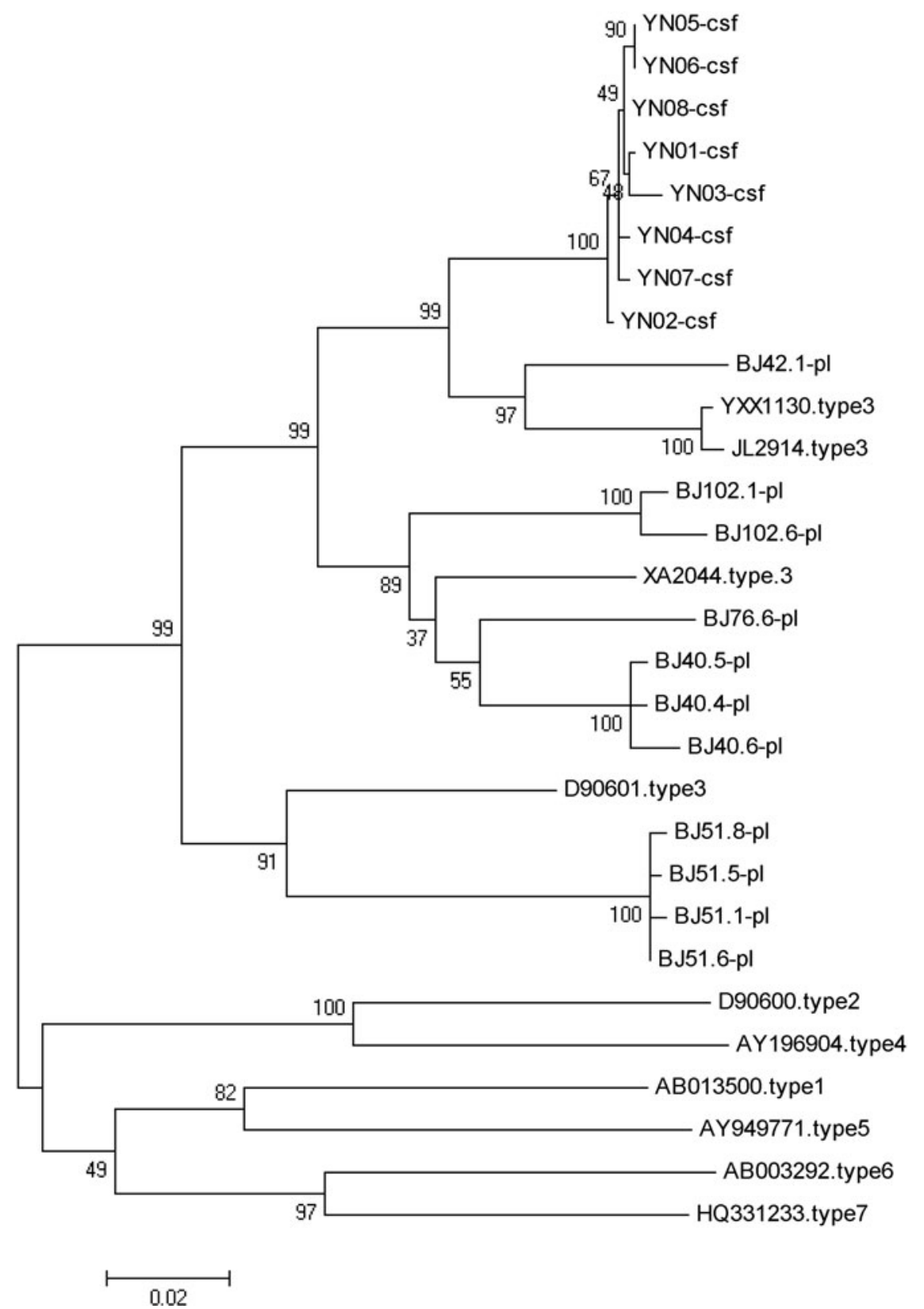

Fig. 1. Reconstruction of phylogenetic tree based on E2 clonal sequences in the CSF from the HIV-infected patient and the blood from five HIV patients co-infected with GBV-C. YNXX-csf is the specimen from the CSF of the HIV-infected patient, BJXX-pl is the specimen from the blood of the HIV-infected patient. The phylogenetic tree is constructed by the neighbor-joining method from the Kimura two-parameter model and evaluated by the bootstrap method using 1000 replicates as implemented in Mega 5.0. Reference strains were obtained from GenBank (NCBI website). The scale bar represents $2 \%$ genetic distance ( 0.02 substitution per site).

of these sequences from six patients belonged to genotype 3, and the eight E2 clones from the CSF of patient YN clustered closely with references YXX1130 and JL2914 (Fig. 1). All nine sequences (one from the 5'-NCR clone and eight from E2 clones) from the CSF of patient $\mathrm{YN}$ generated in this study were deposited in GenBank with accession numbers KF234774-KF234782.

\section{DISCUSSION}

GBV-C is currently believed to be non-pathogenic to humans. Usually, the co-infection of GBV-C in HIV-infected patients is due to the similar transmission route $[3,13,22]$. It appears that GBV-C could slow the progression of HIV disease and improve patient's outcome by a number of possible 
mechanisms. In general, GBV-C co-infection is associated with the reduced activation of $\mathrm{CD} 4+$ and CD8+ T cells in both HIV viraemic and HIV RNAsuppressed patients [23]. Some viral protein products can inhibit HIV replication on CD4 T lymphocytes in vitro [24-28]. Furthermore, GBV-C co-infection in HIV-1-infected patients can lead to the reduced expression of two major HIV-1 co-receptors such as CCR5 and CXCR4 in CD4+ $\mathrm{T}$ cells at an advanced stage of AIDS [29].

Previously, GBV-C has been detected in human lymphoid tissue, serum, muscle, spleen, liver and kidney, but not the brain [30, 31]. Recently, Kriesel et al. reported the concurrent occurrence of both GBV-C genomic RNA and negative-strand replication intermediates in brain tissue of a patient with multiple sclerosis, suggesting that it can be replicated in the CNS of the patient with multiple sclerosis at a very low occurrence rate [32]. However, the presence of GBV-C in the CNS of HIV-1-infected patients has not been reported until now. In the present study, a high GBV-C viral load was detected in the CSF of a HIV/AIDS case with an opportunistic brain infection. In order to detect the incidence of GBV-C in the CSF of HIV/AIDS patients, we tested CSF specimens from five cases of HIV/GBV-C co-infected patients who were free of opportunistic brain infection. However, we failed to detect GBV-C viraemia in any of those five CSF specimens, suggesting that the incidence of GBV-C in the CSF of HIV/AIDS patients is low. Similar results have been observed in HCV, another Flaviviridae virus that is known to be tropic for neural tissue [33, 34].

One of the possibilities for the presence of GBV-C virions in the CSF is that CSF samples are contaminated by blood at the time of lumbar puncture, but this is unlikely due to the absence of blood in CSF samples. The second possibility to explain the findings is the passive transferring of virions via the destroyed blood-brain barrier of patients with opportunistic CNS infection. This hypothesis is supported by the case with neurological complications (cerebral toxoplasmosis, fungal encephalitis) and the CSF from patients without opportunistic brain infection. The third possibility is that GBV-C is 'passively' introduced into the CSF by inflammatory white cell infiltrate. Moreover, the total white blood cell counts in the CSF of the five patients were in the normal range $\left(0-8 \times 10^{6} / 1\right)$, and far below the extent of patient YN $\left(48 \times 10^{6} / 1\right)$ based on medical records. This assumption seems reasonable. The last possibility is that the presence of GBV-C genomic RNA in the CSF samples of the HIV/AIDS patients may be associated with the productive infection in CNS, which is similar to $\mathrm{HCV}$ in the brain of HIV/AIDS patients [35]. However, due to lack of brain tissue, we were unable to determine whether or not GBV-C can replicate in brain tissue.

In addition, we were unable to collect paired blood samples from patient $\mathrm{YN}$ during his hospitalization. Therefore, we did not know if the GBV-C sequences in the blood samples were identical to the nucleic acid sequence in the CSF. Phylogenetic analysis based on the E2 region shows that little genomic diversity is observed in the nucleotides of E2 from the CSF; on average, there is only $0.3 \%$ sequence divergence in all eight E2 nucleotide sequences from each other corresponding to the $7 \cdot 8 \%$ divergence to the reference genotype 3 strains including YXX1130, JL2914 and XA2044 that are isolated from Hebei province in northern China. To some extent, this means little immune pressure in the CSF of GBV-C virus from the host (Fig. 1).

In conclusion, in this study we have detected GBV-C genomic RNA, first in the CSF of the case with HIV/AIDS infection who had an opportunistic brain infection with cerebral toxoplasmosis and fungal encephalitis. Prior to our study, GBV-C was considered for testing only in the blood of the patients with HIV/AIDS co-infection. The high titre of GBV-C viral loads in the CSF reveals the possibility of passive transfer or the active production of GBV-C virions in CNS, although we were unable to detect the GBV-C replication intermediate strand due to the lack of brain tissue. Both hypotheses raise the possibility that the CNS may be another site for GBV-C replication and the destroyed integrity of the blood-brain barrier may play a key role in the invasion GBV-C into the brain. Despite this, the effect of co-infection of GBV-C in the brain of HIV-infected patients remains obscure. Further study on the neuropathological effect of co-infection by GBV-C on the CNS of HIV-infected patients should be conducted.

\section{ACKNOWLEDGEMENTS}

This work was supported by Hepatopathy \& AIDS project of You An Hospital (Z. Liu, BJYAH-2011-062) and the Capital Health Development Research projects (Z. Liu, Capital Development 2011-1011-01), Beijing Key Laboratory for AIDS Research (W. Li, BZ0089), Beijing Natural Science Foundation (7142078 to 
W. Li and 7132077 to D. Mou), Twelfth Key Science and Technology Five Year Plan of China (2012ZX10001-006 to H. Wu and 2012BAI15B08 to D. Chen) and Beijing Municipal Administration of Hospitals Clinical Medicine Development of Special Funding Support (H. Wu, ZY201401).

\section{DECLARATION OF INTEREST}

None.

\section{REFERENCES}

1. Stapleton JT, et al. The GB viruses: a review and proposed classification of GBV-A, GBV-C (HGV), and GBV-D in genus Pegivirus within the family Flaviviridae. Journal of General Virology 2011; 92: 233-246.

2. Blair CS, et al. Prevalence, incidence, and clinical characteristics of hepatitis $\mathrm{G}$ virus/GB virus $\mathrm{C}$ infection in Scottish blood donors. Journal of Infectious Diseases 1998; 178: 1779-1782.

3. Williams CF, et al. Persistent GB virus $C$ infection and survival in HIV-infected men. New England Journal of Medicine 2004; 350: 981-990.

4. Masuko K, et al. Infection with hepatitis GB virus $\mathrm{C}$ in patients on maintenance hemodialysis. New England Journal of Medicine 1996; 334: 1485-1490.

5. Dawson GJ, et al. Prevalence studies of GB virus-C infection using reverse transcriptase-polymerase chain reaction. Journal of Medical Virology 1996; 50: 97-103.

6. Xiang J, et al. Full-length GB virus C (Hepatitis G virus) RNA transcripts are infectious in primary CD4-positive T cells. Journal of Virology 2000; 74: 9125-9133.

7. George SL, Varmaz D, Stapleton JT. GB virus C replicates in primary $\mathrm{T}$ and $\mathrm{B}$ lymphocytes. Journal of Infectious Diseases 2006; 193: 451-454.

8. Seipp S, et al. Hepatotropism of GB virus C (GBV-C): GBV-C replication in human hepatocytes and cells of human hepatoma cell lines. Journal of Hepatology 1999; 30: 570-579.

9. Sergi C, et al. The distribution of HBV, HCV and HGV among livers with fulminant hepatic failure of different aetiology. Journal of Hepatology 1998; 29: 861-871.

10. Laskus T, et al. Lack of evidence for hepatitis G virus replication in the livers of patients coinfected with hepatitis C and G viruses. Journal of virology 1997; 71: 7804 7806.

11. Nerurkar VR, et al. High prevalence of GB virus $\mathrm{C} /$ hepatitis $G$ virus infection among homosexual men infected with human immunodeficiency virus type 1: evidence for sexual transmission. Journal of Medical Virology 1998; 56: 123-127.

12. Scallan MF, et al. Sexual transmission of GB virus $\mathrm{C} /$ hepatitis G virus. Journal of Medical Virology 1998; 55: 203-208.
13. Xiang $\mathbf{J}$, et al. Effect of coinfection with $\mathrm{GB}$ virus $\mathrm{C}$ on survival among patients with HIV infection. New England Journal of Medicine 2001; 345: 707-714.

14. Lefrere JJ, et al. Carriage of GB virus C/hepatitis $G$ virus RNA is associated with a slower immunologic, virologic, and clinical progression of human immunodeficiency virus disease in coinfected persons. Journal of Infectious Diseases 1999; 179: 783-789.

15. Tillmann HL, et al. Infection with GB virus $C$ and reduced mortality among HIV-infected patients. New England Journal of Medicine 2001; 345: 715-724.

16. Birk M, Lindback S, Lidman C. No influence of GB virus $\mathrm{C}$ replication on the prognosis in a cohort of HIV-1-infected patients. AIDS 2002; 16: 2482-2485.

17. Bjorkman $\mathbf{P}$, et al. $\mathrm{GB}$ virus $\mathrm{C}$ during the natural course of HIV-1 infection: viremia at diagnosis does not predict mortality. AIDS 2004; 18: 877-886.

18. Nunnari G, et al. Slower progression of HIV-1 infection in persons with $\mathrm{GB}$ virus $\mathrm{C}$ co-infection correlates with an intact T-helper 1 cytokine profile. Annals of Internal Medicine 2003; 139: 26-30.

19. Stapleton JT, Williams CF, Xiang J. GB virus type C: a beneficial infection? Journal of Clinical Microbiology 2004; 42: 3915-3919.

20. Jung S, et al. HIV entry inhibition by the envelope 2 glycoprotein of GB virus C. AIDS 2007; 21: 645-647.

21. Boudko DY. Molecular basis of essential amino acid transport from studies of insect nutrient amino acid transporters of the SLC6 family (NAT-SLC6). Journal of Insect Physiology 2012; 58: 433-449.

22. Liu Z, et al. Prevalence of GB virus type $\mathrm{C}$ viraemia in MSM with or without HIV-1 infection in Beijing, China. Epidemiology and Infection 2012; 140: 2199-2209.

23. Bhattarai N, et al. GB virus $C$ envelope protein E2 inhibits TCR-induced IL-2 production and alters IL-2-signaling pathways. Journal of Immunology 2012; 189: 2211-2216.

24. George SL, et al. The GB virus C (GBV-C) NS3 serine protease inhibits HIV-1 replication in a CD4+ $\mathrm{T}$ lymphocyte cell line without decreasing HIV receptor expression. PLOS ONE 2012; 7: e30653.

25. Stapleton JT, et al. GBV-C viremia is associated with reduced CD4 expansion in HIV-infected people receiving HAART and interleukin-2 therapy. AIDS 2009; 23: 605-610.

26. Xiang $\mathbf{J}$, et al. An 85 -aa segment of the GB virus type $\mathrm{C}$ NS5A phosphoprotein inhibits HIV-1 replication in CD4+ Jurkat $\mathrm{T}$ cells. Proceedings of the National Academy of Sciences USA 2006; 103: 15570-15575.

27. Koedel Y, et al. Peptides derived from a distinct region of GB virus $\mathrm{C}$ glycoprotein E2 mediate strain-specific HIV-1 entry inhibition. Journal of Virology 2011; 85: 7037-7047.

28. Vahidnia F, et al. Acquisition of GB virus type $\mathrm{C}$ and lower mortality in patients with advanced HIV disease. Clinical Infectious Diseases 2012; 55: 1012-1019.

29. Schwarze-Zander C, et al. GB virus C coinfection in advanced HIV type-1 disease is associated with low CCR5 and CXCR4 surface expression on CD4(+) T-cells. Antiviral Therapy 2010; 15: 745-752. 
30. Tucker TJ, Smuts HE. Review of the epidemiology, molecular characterization and tropism of the hepatitis G virus/GBV-C. Clinica y Laboratorio 2001; 47: 239-248.

31. Radkowski M, et al. Lack of GB virus $C /$ hepatitis $G$ virus sequences in cerebrospinal fluid in patients with central nervous system infections. Scandinavian Journal of Infectious Diseases 1998; 30: 539.

32. Kriesel JD, et al. Deep sequencing for the detection of virus-like sequences in the brains of patients with multiple sclerosis: detection of GBV-C in human brain. PLOS ONE 2012; 7: e31886.
33. Andraud M, et al. Living on three time scales: the dynamics of plasma cell and antibody populations illustrated for hepatitis a virus. PLoS Computational Biology 2012; 8: e1002418.

34. Laskus T, et al. Detection and analysis of hepatitis C virus sequences in cerebrospinal fluid. Journal of Virology 2002; 76: 10064-10068.

35. Bagaglio S, et al. Hepatitis $\mathrm{C}$ virus populations in the plasma, peripheral blood mononuclear cells and cerebrospinal fluid of HIV/hepatitis C virus-co-infected patients. AIDS 2005; 19 (Suppl. 3): S151-165. 